\title{
Application of Flushing Tanks in Simple Sewer Networks for In-Sewer Sediment Erosion and Transport
}

\section{Reza H.S.M. Shirazi, Patrick Willems and Jean Berlamont}

The principal objective of urban drainage systems is to transport the aqueous and solid wastes emanating from domestic, industrial and storm sources for treatment and disposal. The solids that enter the system are often a cause for concern as they may settle out to form permanent or semi-permanent deposits on sewer inverts which can generate problems such as hydraulic restrictions, reduction in the design flow capacity of the sewers, and increase of the risks of surcharging during storm events. Generally, in-pipe deposits result from accumulation of sediments during dry weather flow (DWF) periods and during the recession of storms (Skipworth et al., 2001). Solid materials largely originate from domestic and industrial wastewater and from unpaved catchment areas (Dettmar et al., 2002). The sediment deposition tendency is different depending on the location of a sewer in a network and the characteristics of the conduit such as size, gradient and shape. Deposition will occur at a rate depending upon the flow characteristics, the nature of the particles and their concentration in suspension near the bed (Fraser \& Ashley, 1999).

To account for the effects of sediments in sewer systems, an appropriate sediment transport modeling should be carried out which needs to consider the following (Fraser et al., 2005):

- To produce rapid, detailed, continuous hydraulic simulations for sewer flows with long term durations;

Shirazi, R., P. Willems and J. Berlamont. 2010. "Application of Flushing Tanks in Simple Sewer Networks for In-Sewer Sediment Erosion and Transport." Journal of Water Management Modeling R236-07. doi: 10.14796/JWMM.R236-07.

(C) CHI 2010 www.chijournal.org ISSN: 2292-6062 (Formerly in Dynamic Modeling of Urban Water Systems. ISBN: 978-0-9808853-3-0) 
- To determine the most likely locations of sediment deposition using a pipe-by-pipe analysis;

- To predict approximate depths of sedimentation at locations identified previously so as to rank potentially problematic locations; and

- To predict sediment concentrations during dry weather and storm events allowing for potential erosion volumes from deposited beds.

The major requirement in urban drainage design is to ensure that sediment would be transported through sewer pipes at the same rate that it approaches the sewer network without any long term build-up of sediment deposits (May, 2001). It is important to note that since flow rates and sediment loads in sewer systems can vary considerably with time, it is unrealistic to expect to be able to design a sewer network so that no deposition would occur under various flow conditions. Accordingly, sewers should be designed to transport sediment at a rate sufficient to limit the depth of deposition to a specified proportion of the pipe section to maintain the required hydraulic characteristics of the conduit. According to Bertrand-Krajewski (2002), two important issues regarding sewer system design are:

- How to avoid or at least limit deposition in new sewers by means of appropriate rules based on sewer shapes, slopes and flow velocities; and

- How to cleanse deposits by means of appropriate flushing and mechanical devices.

In fact, avoiding deposition is not always promising, particularly in flat regions, where the necessary slopes for sewer pipes to be self-cleansing are not available due to the costs of deep excavations and pumping systems (especially in the most upstream parts of the network). Nevertheless, the deposited particles (see Figure 7.1) may be re-entrained later by means of higher flows in the network. The magnitude of erosion varies in response to the time varying hydraulics. Along with sufficient flow velocity and bottom shear stress, successive occurrence of high flow conditions, which would force deposited particles to unhinge, has a substantial effect on re-entrainment of the deposits. In this regard, the shear stress is the key parameter responsible for the start of sediment transport when its critical value for certain sediment characteristics is exceeded.

In addition, given that designing sewer systems to be self-cleansing is not always possible, particularly in flat regions, the use of flush tanks that generate controlled flush waves into the connected sewer system could be suitable. Flushing is able to realize a preventive strategy under economical and ecological conditions by generating flush waves continuously or quasi-continuously 
(Dettmar \& Staufer, 2005). The operation of the flushing devices is usually based on the storage and successive release of flushing volumes, able to scour deposited sediments and to transport them downstream towards steeper sewer sections (Campisano et al., 2004).
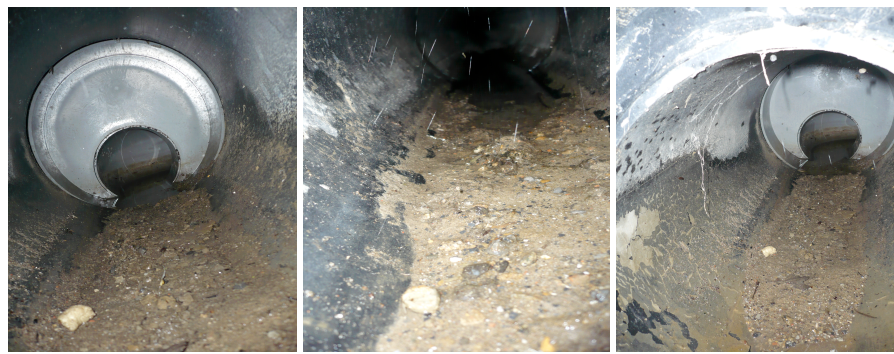

Figure 7.1 Deposits in sewers.

\section{Characteristics of the Flushing Tank}

A flushing tank is evaluated in this chapter regarding its capabilities for generating the required scouring forces (i.e. shear stresses) throughout sewer pipes, as a result of the flush waves (outflow discharges) released in flushing cycles. The flushing device (provided by Keramo-Steinzeug, Belgium) is comprised of a tank $1 \mathrm{~m}$ high, with a diameter of $1.2 \mathrm{~m}$ and a volume of about $450 \mathrm{~L}$, releasing a flushing discharge $<27 \mathrm{~L} / \mathrm{s}$ and $>19 \mathrm{~L} / \mathrm{s}$ that lasts for at least $20 \mathrm{~s}$. Surface runoff reaches the flushing device by means of a connection on the side wall of the tank. In rainy periods the water level in the tank rises until the water height exceeds a given level. Then the excess flow is bypassed through a pipe toward the exit section, and then by means of a hydraulic process, the stored water flows through the outfall of the device and initiates a flush wave into the connected pipe. The flushing device is illustrated in Figure 7.2.
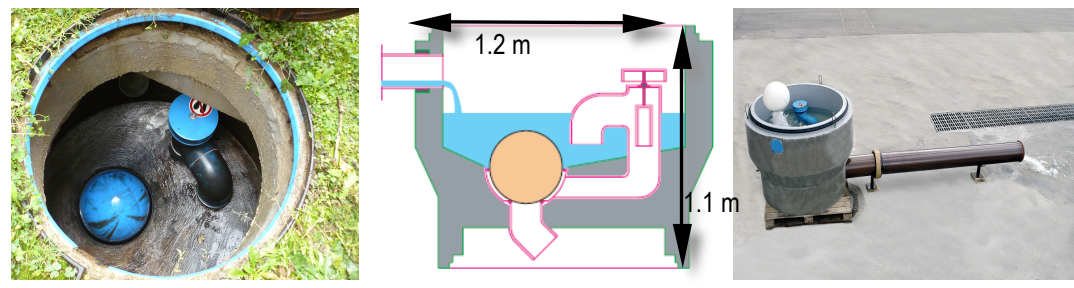

Figure 7.2 Illustrations of the flushing tank. 
There is a variation in outflow discharge while the flushing occurs, which is due to the reduction in the initial water level in the tank. Hence, based on Bernoulli's equation, head loss computations and the geometrical characteristics of the flushing device, the outflow from the flushing device (flush wave) is calculated (Bouteligier et al., 2006) as shown in Figure 7.3.

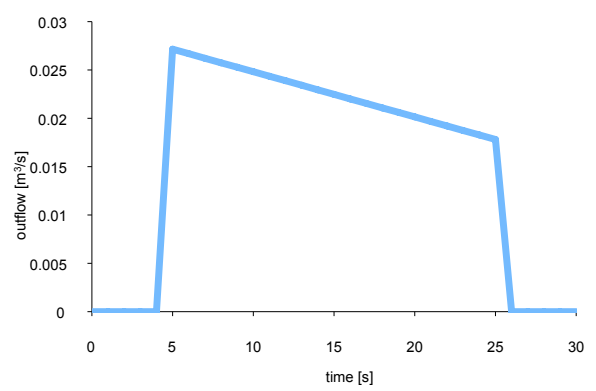

Figure 7.3 The outflow hydrograph for a flushing cycle.

\section{Implementing the Flushing Tank in Sewer Networks}

The idea of using the mentioned type of flushing device is to benefit from its capacity to generate a relatively high volume of inflow into parts of a sewer network in a relatively short period of time. This high volume of flow assists in scouring the settled particles and transporting them towards the downstream parts of the network. In fact, as the generated outflow discharge of each flush is about $20 \mathrm{~L} / \mathrm{s}$, the characteristics of the pipes receiving the flushes (pipe diameter and bottom slope) could be important. There would be notable difference in the generated flush characteristics in the connected pipes with various diameters and slopes. Also, pipe length is an important parameter influencing the flush characteristics propagating through the network. If the lengths of the pipes are too long, flushing might not be effective. Therefore, it is important to install flushing devices in proper locations to generate the required shear stresses where the existing situation does not comply with self-cleansing conditions (H.S.M. Shirazi et al., 2008). The objective of this chapter is to assess whether by implementing flushing tanks in a simple network, erosion of the settled particles and their removal from the sewer system could be achieved. 


\subsection{Methodology}

\subsubsection{InfoWorks CS}

Recently, the field of urban drainage design has benefited from the availability of sewer flow quality modeling tools together with hydrodynamic simulation packages. Thus, together with general hydraulic results generated by hydrodynamic modeling, the possibility to properly model the impact of sediment accumulation in sewer systems as well as the amount of sediments and pollutants that are transported into receiving waters or treatment plants has been developed. These lead to an enhanced design and management of urban drainage systems. In this study, an evaluation based on simulations carried out with version 9.0 of InfoWorks CS (Wallingford Software, UK) regarding application of a flushing tank as a tool for eroding deposited sediments from a simple sewer network is presented. The hydrodynamic modeling was comprised of implementing InfoWorks CS to assess the eroding capability of the generated flush waves regarding sediment removal and transport, applying the model based on the shear stress estimation in the software (the KUL model developed by Bouteligier et al., 2002). This model will be discussed in section 7.1.2.

\subsubsection{Sediment Transport Modeling}

Sediment deposit could result in the change in the hydrodynamic behavior of the network due to pipe cross sectional modifications, and could possibly lead to the occurrence of surcharging or even flooding. Reliable modeling requires the effect of sediments on the hydraulic features of the flow to be considered. This indeed demands comprehensive knowledge of the sediment behavior inside the sewer pipes and the related phenomena linked to sediment transport (entrainment, deposition, and re-entrainment). For a proper sediment transport model a precise definition of sediment characteristics (particle size, density, concentration, etc.) in the catchment and in the sewer network is required. Particle characteristics and the prevailing hydraulic conditions are important factors regarding proper estimations of the mode of transport.

It is known that at high enough shear stresses, the re-entrainment of sediment particles starts to occur with small particles that have high rate of mobility compared to the larger and heavier ones (Bouteligier et al., 2006). Fine silt particles and low-density organic materials can be transported relatively easily by the flow velocities typical of gravity sewers. However, uneconomically steep 
gradients would be required to achieve this transport mode for the heavier inorganic fractions such as medium/coarse sand and gravel (May, 2001). The flow characteristics are important regarding the start of the sediment transport phenomenon. For instance the inorganic granular material moving along the bed in sewers, which may be considered as bed-load, will rarely travel in true suspension during dry weather flow (Ashley \& Verbanck, 1996).

As it is acknowledged by many researchers (Ashley et al., 1998 and Skipworth et al., 2001), sewer sediment deposits are heterogeneous. Even in the same location within a sewer network in-pipe deposits with significantly different characteristics can develop. Therefore, assigning valid sediment characteristics in water quality modeling is a rather uncertain task. Nevertheless, sediment transport modeling cannot be achieved without setting these parameters, and some relevant values need to be specified for sediment characteristics. As an example, the characteristic of typical sewer sediment classes explained by Stovin et al. (2005) is presented in Table 7.1.

Table 7.1 Characteristic of typical sewer sediment classes (Stovin et al., 2005).

\begin{tabular}{lccc}
\hline In-Sewer Sediment Type & $\mathrm{d}_{50}(\mathrm{~mm})$ & Density $\left(\mathrm{kg} / \mathrm{m}^{3}\right)$ & Estimated Fall Velocity $(\mathrm{mm} / \mathrm{s})$ \\
\hline Gravel & 10 & 2650 & 756 \\
Sand & 3 & 2650 & 380 \\
Grit & 0.75 & 2650 & 136 \\
Gross Solids & 2 & 1030 & 25 \\
Sanitary-Stormwater & 0.06 & 2500 & 3 \\
Sanitary-DWF & 0.04 & 1400 & 0.3 \\
\hline
\end{tabular}

Generally, the main objective of sediment transport modeling is to obtain the track of sediment accumulation in a sewer system. InfoWorks CS accomplishes this by offering the water quality simulation module comprised of three different sediment transport models: Ackers-White based on concentration comparison (Ackers, 1991), Velikanov based on energy dissipation (Zug et al., 1998), and KUL based on shear stress comparison (Bouteligier et al., 2002).

For sediment transport modeling in this chapter, the KUL model was implemented. According to the KUL model, which is based on Shields concept, if the actual shear stress $\tau$ is below the critical shear stress for deposition $\left(\tau_{c r-d e p o s i t i o n}\right)$, then deposition will occur. If the actual shear stress value $\tau$ is inbetween the critical shear stress for deposition and that for erosion $\left(\tau_{c r}\right.$ deposition $<\tau<\tau_{\text {cr-erosion }}$ ), then neither erosion nor deposition occurs and all suspended sediments are transported along the conduit. If the actual shear stress $\tau$ exceeds the critical shear stress for erosion $\tau_{\text {cr-erosion }}\left(\tau>\tau_{c r-\text {-rosion }}\right)$ then erosion 
would occur. The shear stress is calculated as a function of the water head, the hydraulic radius and the (friction) slope of the flow according to Equation 7.1. The velocity is assumed to be uniform and is computed according to Equation 7.2.

$$
\begin{aligned}
& \tau=\frac{\lambda_{c}}{8} \rho v^{2} \\
& v=\sqrt{\frac{8 g}{\lambda_{c}}} \sqrt{R S_{0}}
\end{aligned}
$$

where:

$$
\begin{aligned}
\tau & =\text { shear stress }\left(\mathrm{N} / \mathrm{m}^{2}\right) \\
\lambda_{c} & =\text { composite friction factor }(-), \\
\rho & =\text { water density }\left(\mathrm{kg} / \mathrm{m}^{3}\right), \\
v & =\text { flow velocity }(\mathrm{m} / \mathrm{s}), \\
g & =\text { gravitational acceleration }\left(\mathrm{m} / \mathrm{s}^{2}\right), \\
R & =\text { hydraulic radius }(\mathrm{m}), \text { and } \\
S_{0} & =\text { pipe invert slope }(\mathrm{m} / \mathrm{m}) .
\end{aligned}
$$

The critical shear stresses for deposition and erosion are calculated based on the formula in Equation 7.3 and Equation 7.4 (Bouteligier et al., 2002).

$$
\begin{aligned}
& \tau_{\text {cr,erosion }}=\gamma_{\text {erosion }} g(s-1) \rho d_{50} / 1000 \\
& \tau_{\text {cr,deposition }}=\gamma_{\text {deposition }} g(s-1) \rho d_{50} / 1000
\end{aligned}
$$

where

$$
\begin{aligned}
\gamma_{\text {deposition }} & =\text { deposition parameter }(-), \\
\gamma_{\text {erosion }} & =\text { erosion parameter }(-) \text { and }\left(\gamma_{\text {deposition }} \leq \gamma_{\text {erosion }}\right) \\
S & =\text { specific sediment density }(-), \text { and } \\
d_{50} & =\text { sediment particle size }(\mathrm{mm}) .
\end{aligned}
$$

In fact, $\gamma_{\text {deposition }}$ and $\gamma_{\text {erosion }}$ are the dimensionless critical shear stresses which specify the boundaries for deposition and erosion respectively.

The median sediment particle size $\left(d_{50}\right)$ for InfoWorks modeling in this chapter was assumed to be equal to $0.1 \mathrm{~mm}$ for sanitary sediment and $0.2 \mathrm{~mm}$ to $1.5 \mathrm{~mm}$ for catchment sediment. This is compatible with the data presented in Table 7.1. To verify the effect of variations in sewer network characteristics on the evolution of sediment depths throughout the network (sediment transport), various combinations of these characteristics were considered. The various sewer network combinations are presented in Table 7.2, in which SF1 accounts for the catchment sediment and SF2 corresponds to sanitary sediment. 
Table 7.2 The characteristics of the sewer network.

\begin{tabular}{ccccccc}
\hline Sewer Network & $\begin{array}{c}\text { Slope } \\
(\mathrm{m} / \mathrm{m})\end{array}$ & $\begin{array}{c}\text { DWF } \\
\left(\mathrm{m}^{3} / \mathrm{s}\right)\end{array}$ & $\begin{array}{c}\text { Sediment } \\
\text { Type }\end{array}$ & $\begin{array}{c}\text { Concentration } \\
(\mathrm{mg} / \mathrm{l})\end{array}$ & $\mathrm{d}_{50}(\mathrm{~mm})$ & $\begin{array}{c}\text { Particle } \\
\text { Density } \\
\left(\mathrm{kg} / \mathrm{m}^{3}\right)\end{array}$ \\
\hline Conduit/Network & 0 & 0.003 & SF1 & 150 & $0.2-1.5$ & 2650 \\
Conduit/Network & 0.001 & \multirow{2}{*}{0.003} & SF1 & 150 & $0.2-1.5$ & 2650 \\
& & & SF2 & 150 & 0.1 & 1800 \\
Conduit/Network & 0.002 & \multirow{2}{*}{0.003} & SF1 & 150 & $0.2-1.5$ & 2650 \\
Conduit/Network & \multirow{2}{*}{0.003} & \multirow{2}{*}{0.003} & SF2 & 150 & 0.1 & 1800 \\
& & & SF1 & 150 & $0.2-1.5$ & 2650 \\
Conduit/Network & 0.004 & \multirow{2}{*}{0.003} & SF2 & 150 & 0.1 & 1800 \\
& & & SF1 & 150 & $0.2-1.5$ & 2650 \\
Conduit/Network & 0.005 & \multirow{2}{*}{0.003} & SF1 & 150 & 0.1 & 1800 \\
& & & SF2 & 150 & $0.2-1.5$ & 2650 \\
\end{tabular}

\subsubsection{Model Set-up}

\section{Conduit model}

Initially, a simple network model was created in InfoWorks CS to produce the required hydrodynamic simulations. The sewer network consisted of a series of straight and sequentially connected pipes. The pipe diameters were $400 \mathrm{~mm}$ and each had a length of $10 \mathrm{~m}$, comprising an overall length of $50 \mathrm{~m}$. To study the influence of the network characteristics on the flush wave propagation in the sewer stretch, the model was run for various combinations of pipe slopes, median sediment particle size $\left(d_{50}\right)$, and sediment concentration (see Table 7.2 above). The conduit model is illustrated in Figure 7.4.

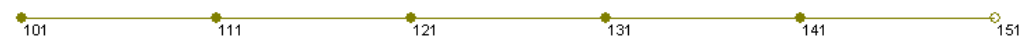

Figure 7.4 The conduit model for a series of pipes with identical lengths, diameters and invert slopes.

Regarding the dry weather sediment build-up modeling, it was important to reach an equilibrium condition before any implementation of flushing tanks would be considered. The DWF was considered to be equal to $0.003 \mathrm{~m}^{3} / \mathrm{s}$. This value was introduced at certain manholes in the model. The timestep was $1 \mathrm{~s}$, and a total duration of $5 \mathrm{~d}$ sedimentation (DWF period) was considered. 
After the initial period of sediment build-up, the effect of flushing waves emitted from the implemented flushing tanks was modeled. Initially, the effect of flush waves released from one flushing tank implemented at the most upstream manhole on sediment removal was analyzed. Various flushing events were assumed ( 1 flush, 7 flushes with 5 min intervals, 10 flushes with $10 \mathrm{~min}$ intervals, and 20 flushes with 3 min intervals). After the flushing events occurred in the network, their effects on sediment transport were assessed. Whenever the upstream flushing tank was found incapable of generating required criterion for sediment erosion and transport through the network, more flush tanks were proposed to be applied in downstream manholes. Next, having implemented more flushing tanks in potentially effective locations, the results for sediment erosion and transport in the network was analyzed and the positive and negative outcomes of such applications were assessed.

As already mentioned, the KUL model was utilizeded for the sediment transport modeling (see Section 7.1.2 above). In order to model deposition and erosion as two distinct criteria regarding in-sewer sediment behavior, it was necessary to specify the required boundaries in the modeling procedure. The boundaries between settlement of particles and their erosion (re-entrainment) were defined by means of $\gamma$ parameters in the KUL model, which are principally the Shields dimensionless shear stress parameter (see Equations 7.3 and 7.4 above).

In order to obtain the dimensionless shear stresses (Shields parameters) regarding the deposition boundary conditions $\left(\gamma_{\text {deposition }}\right)$, the particle Reynolds number for each sediment particle size (within the range $0.1 \mathrm{~mm}$ to $1.5 \mathrm{~mm}$ ) and for each of the considered slopes was calculated and then the Shields parameter was detained from the Shields graph (see Figure 7.5 and Table 7.3). Then, for the dimensionless shear stresses for the erosion boundary conditions, the corresponding values of $\gamma_{\text {deposition }}$ were modified in a way to create the required domain for sediment transport in between deposition and erosion. The results are illustrated in Figure 7.6.

Table 7.3 Flow characteristics for diverse invert slopes in the conduit.

\begin{tabular}{cccccc}
\hline $\begin{array}{c}\text { Slope } \\
(\mathrm{m} / \mathrm{m})\end{array}$ & $\begin{array}{c}\text { Average Water } \\
\text { Depth }(\mathrm{m})\end{array}$ & $\begin{array}{c}\text { Hydraulic } \\
\text { Radius }(\mathrm{m})\end{array}$ & $\begin{array}{c}\text { Mean Velocity } \\
(\mathrm{m} / \mathrm{s})\end{array}$ & $\begin{array}{c}\text { Reynolds } \\
\text { Number }(-)\end{array}$ & $\begin{array}{c}\text { Average Bed } \\
\text { Shear Stress } \\
\left(\mathrm{N} / \mathrm{m}^{2}\right)\end{array}$ \\
\hline 0 & 0.12 & 0.0684 & 0.16 & 43776 & 0.0812 \\
1 & 0.075 & 0.0482 & 0.29 & 55912 & 0.2737 \\
2 & 0.065 & 0.0372 & 0.35 & 52080 & 0.4207 \\
3 & 0.05 & 0.0301 & 0.398 & 47919.2 & 0.5713 \\
4 & 0.045 & 0.0277 & 0.433 & 47976.4 & 0.6881 \\
5 & 0.035 & 0.0245 & 0.461 & 45178 & 0.8046 \\
\hline
\end{tabular}




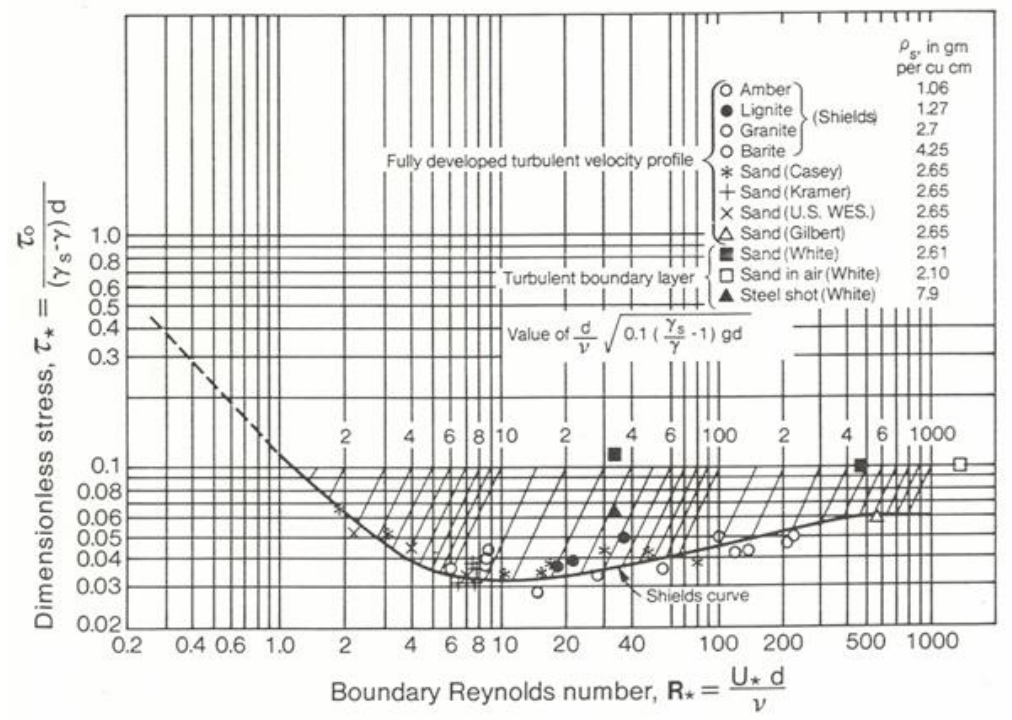

Figure 7.5 The Shields diagram for sediment deposition-erosion (ASCE 1975).

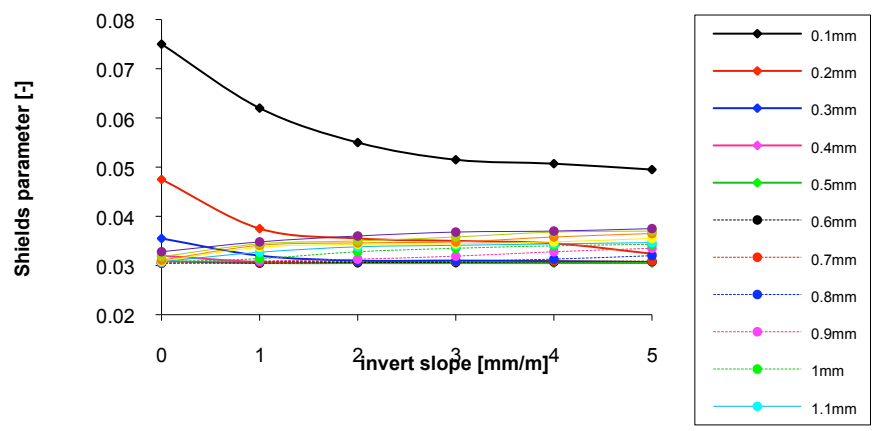

Figure 7.6 The dimensionless shear stress boundary conditions for deposition (left) and erosion (right) from the Shields diagram based on the prevailing hydraulic conditions. 


\section{Network model}

In the second phase, a few more branch pipes were added to the initial network and the same analyses were repeated to evaluate the overall effects of added parts on sediment build-up and transport. Again, in the performed sediment transport modeling, the effect of implementing numerous flush tanks in various parts of the network over sediment bed modifications (sediment entrainment, transport, and re-deposition) and changes in bed profiles was evaluated. The final objective was to evaluate whether by implementing flushing tanks in such a network, erosion of the settled particles and removing them out of the system could be reached. As done for the conduit model, for verifying the effect of variations in sewer network characteristics on the evolution of sediment depths throughout the network (sediment build-up and transport), various combinations of these characteristics were considered for the mentioned network, and then proper comparisons were accomplished. Thus, diverse combinations of pipe slope, sediment characteristics, and DWF in the network was considered (see Table 7.2 above). The network model is illustrated in Figure 7.7. In fact, the modeling concepts and the aims were the same as the case of the conduit model, but in a broader scale.

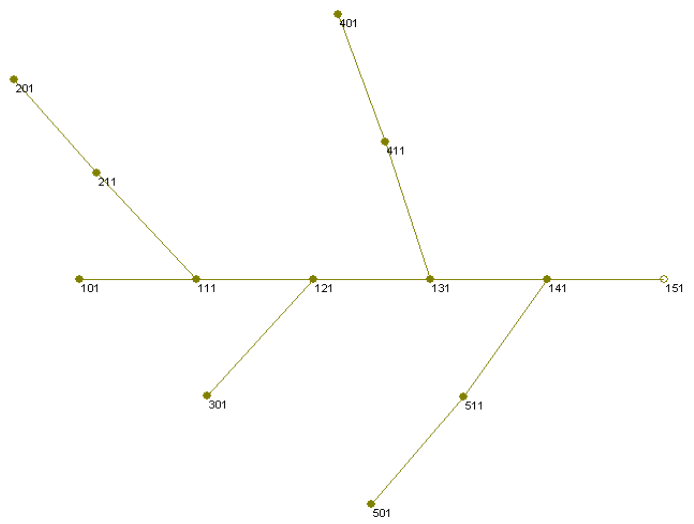

Figure 7.7 The network model for pipes with identical diameters $(400 \mathrm{~mm})$ and various invert slopes.

\subsection{Results and Discussion}

\subsubsection{Sediment Build-up along the Conduit During DWF Period}

The main objective in this study was to model the evolution of sedimentation 
and erosion in a simple sewer network. In order to reach to a proper conclusion, it was important to see the sediment build-up along sewers in a way to comply with physical measures. For such a purpose, a constant DWF equal to $0.003 \mathrm{~m}^{3} / \mathrm{s}$ within a $5 \mathrm{~d}$ period was assumed in order to leave enough time for the inflowing particles from the catchment to settle on sewer inverts before any simulation of the effects of flushes would be done. In fact, the effect of flushes could not be assessed if the initial conditions were not modeled properly. Therefore, the modeling attempts were managed in a way to reach the sediment build-up all over the considered network; that is, to reach an equilibrium condition for the sediment layer along sewer inverts.

The problem to deal with was the fact that sediment build-up and entrainment was very sensitive to the prevailing hydraulic features of the network. In fact, various network characteristics would lead to diverse sediment build-up scenarios. Therefore, to reach to an equilibrium condition for sediment buildup, it was important to change the sediment and flow characteristics in different networks with dissimilar pipe slopes. In other words, due to the large effect of invert slopes on the possibility of forming deposits on the sewer invert levels, only for certain pipe configurations the particle settlement was reached. Another important issue was the fact that moving from the upstream toward the downstream part of the network, the amount of flow would increase due to the existence of manholes which would provide excessive flow into the network. This in turn would affect the sedimentation in downstream pipes and as a result less sediment would settle in those pipes in the network. In fact, the sedimentation was noticed only in cases where the actual shear stresses at bed were below the critical shear stresses for deposition (based on the Shields diagram). For the mentioned model, the sedimentation occurred only in the following cases (the dashed lines) as indicated in Table 7.4. Some results of sediment build-up for pipes with various slopes can be observed in the following figures (Figure 7.8 through Figure 7.10).

Table 7.4 The dashed lines indicate the situation where deposition of particles were modeled along the pipe invert level.

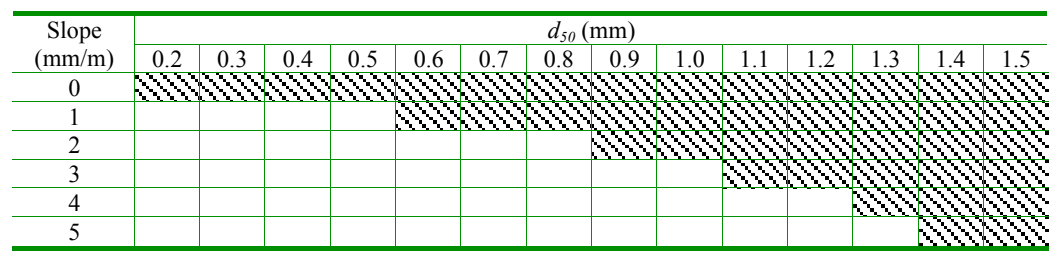



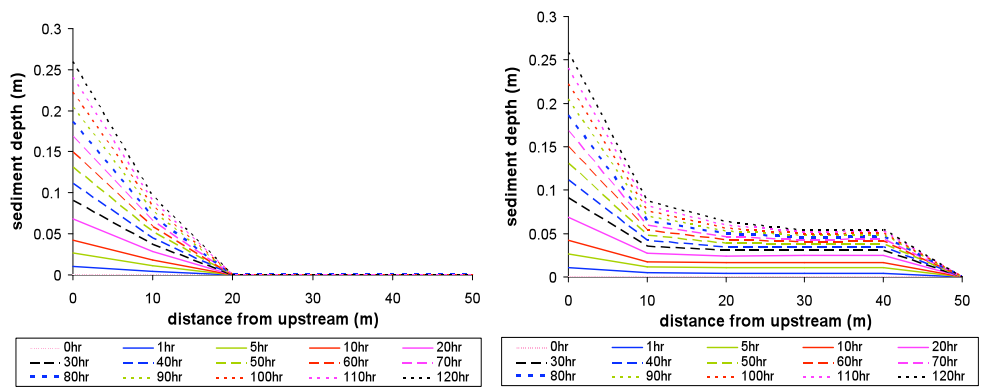

Figure 7.8 Sediment build-up in the conduit with slope $=0.001 \mathrm{~m} / \mathrm{m}$ for particles with $d_{50}=0.6 \mathrm{~mm}$ (left) and $1.2 \mathrm{~mm}$ (right).
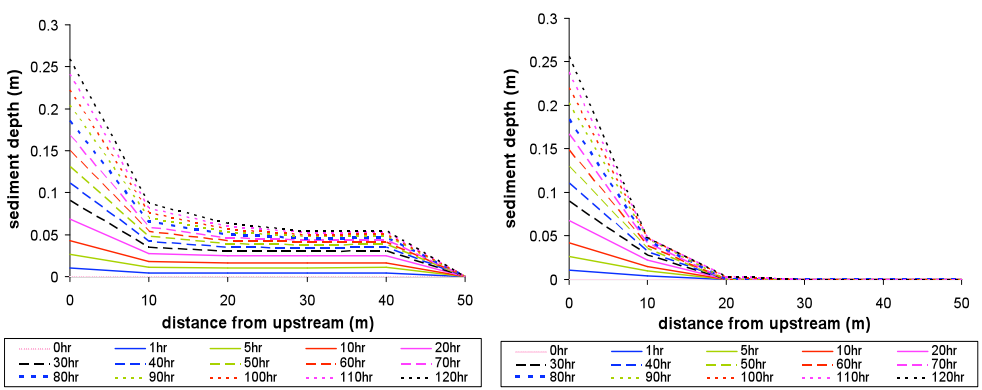

Figure 7.9 Sediment build-up in conduits with slope $=0.001 \mathrm{~m} / \mathrm{m}$ (left) and $0.002 \mathrm{~m} / \mathrm{m}$ (right) and particles with $d_{50}=0.9 \mathrm{~mm}$.
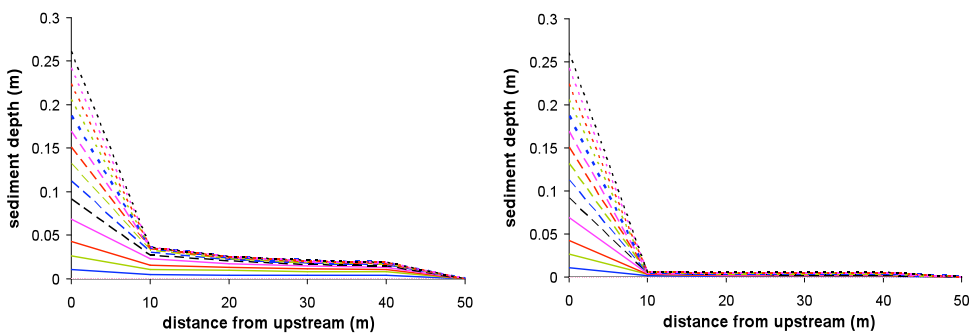

\begin{tabular}{|c|c|}
\hline $\begin{array}{c}\text { Ohr } \\
-.30 \mathrm{hr}\end{array}$ & ${ }_{-4}^{1 \mathrm{hr} r}$ \\
\hline
\end{tabular}

\begin{tabular}{|c|c|c|}
\hline & ${ }_{-1 \mathrm{hr}}$ & $5 \mathrm{hr}$ \\
\hline
\end{tabular}

Figure 7.10 Sediment build-up in conduits with slope $=0.003 \mathrm{~m} / \mathrm{m}$ (left) and $0.005 \mathrm{~m} / \mathrm{m}$ (right) and particles with $\mathrm{d}_{50}=1.5 \mathrm{~mm}$. 
By observing the results, the effect of various particle sizes and invert slopes can be clearly noticed. In fact, the previous figures show that any increase in the invert slope would result in lower deposition rate along the conduit, and illustrate the fact that the erosion of the settled particles would be eased especially in downstream parts of the sewer length. Besides, larger particles would form higher sediment bed depths along the pipes inverts.

\subsubsection{Sediment Erosion by means of Flushes in the Conduit Model}

After the DWF sediment build-up period was over, it was time to assess the effect of flushing waves on sediment removal. In general, to properly evaluate the effect of flush waves on sediment erosion, it was important to observe the evolution of the sediment massflow and concentration throughout the network, and to compare the changes in hydraulic characteristics such as flow velocity, discharge, sediment concentration and flux.

It is expected that at the moment the flush wave passes along the pipes, the sediment depth would be reduced (due to re-entrainment of deposited particles by the flush wave) and the suspended sediment concentration would be increased. Later, when the peak of the flush wave diminishes from its maximum, sedimentation starts to occur due to the reduction in the energy of the wave. In other words, the reduction in the carrying capacity of the flow, which coincides with the decrease in flow velocity, would lead to the decline in the sediment concentration and simultaneously to the development of sediment deposit layer.

For the required evaluations, various types of flushing events were assumed and their effects were compared (1 flush, 7 flushes with 5 min intervals, 10 flushes with $10 \mathrm{~min}$ intervals and 20 flushes with $3 \mathrm{~min}$ intervals). The comparisons are depicted in Figure 7.11 through 7.13.
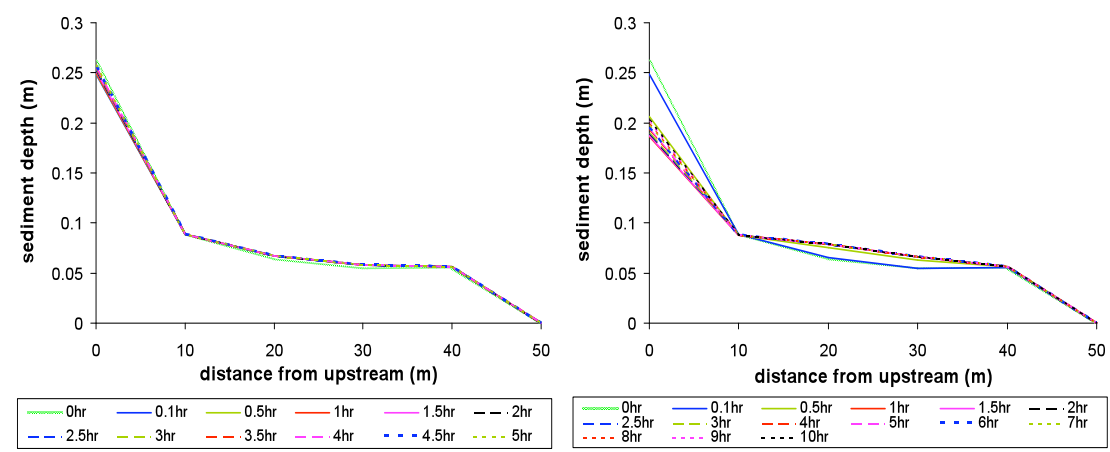

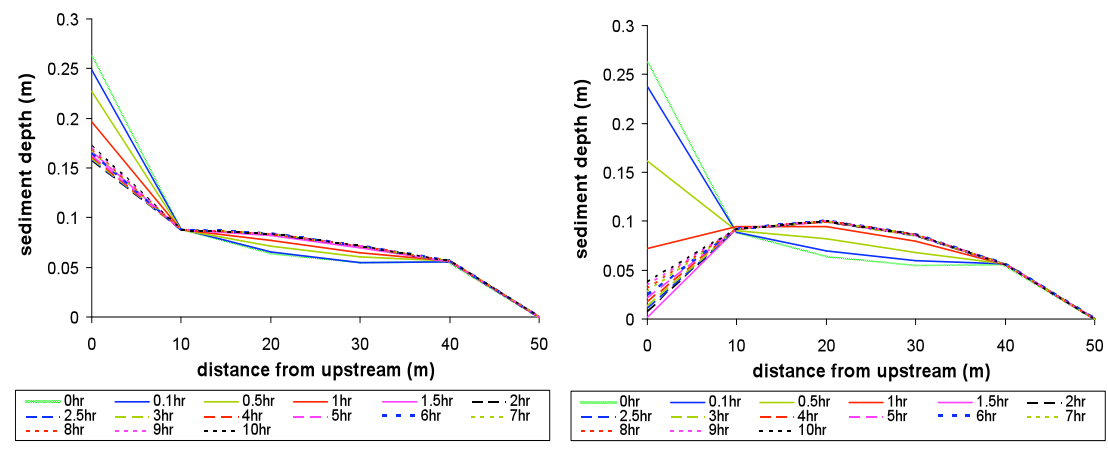

Figure 7.11 Sediment erosion by means of flushes in the conduit with slope $=0.001 \mathrm{~m} / \mathrm{m}$ and particle $d_{50}=0.9 \mathrm{~mm}: 1 \mathrm{flush}$ ( $u$. left), 7 flushes with 5 min intervals (u. right), 10 flushes with 10 min intervals (l. left), and 20 flushes with 3 min intervals (I. right).
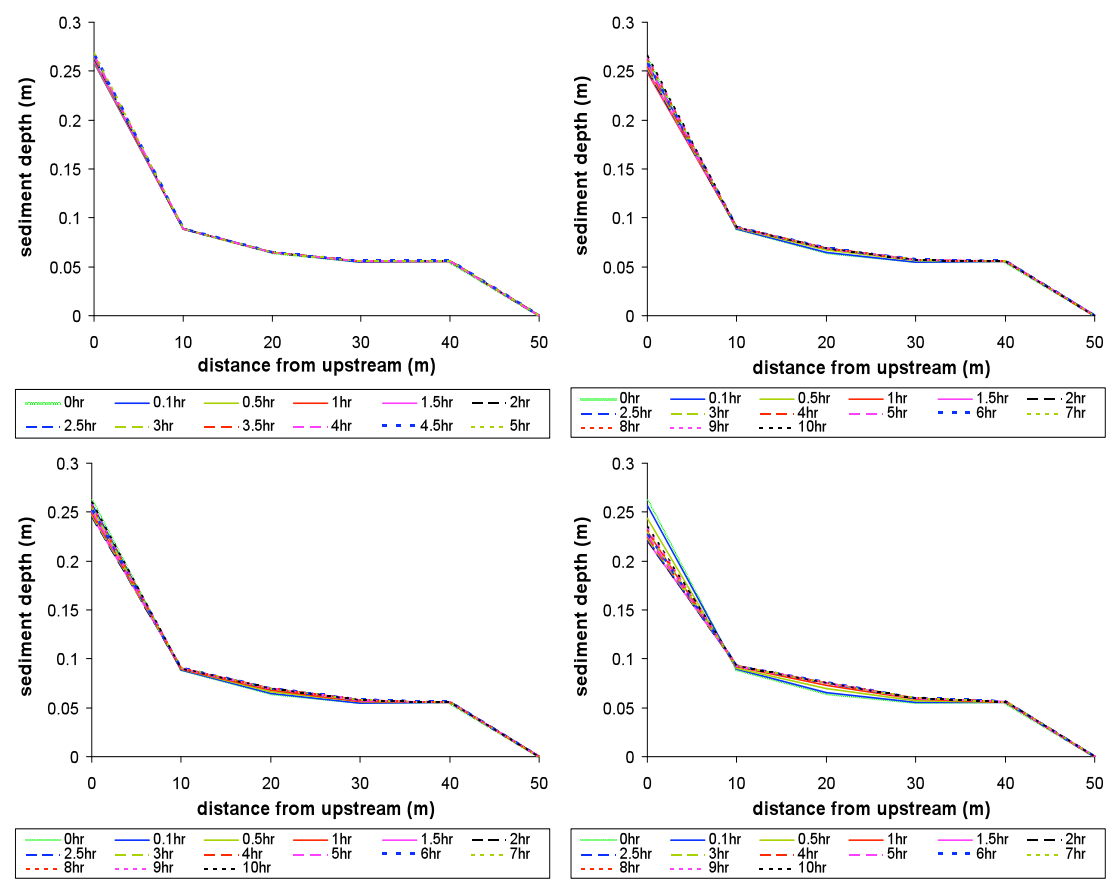

Figure 7.12 Sediment erosion in the conduit with slope $=0.001 \mathrm{~m} / \mathrm{m}$ and particle $d_{50}=1.2 \mathrm{~mm}$ due to the effect of flushes: 1 flush (u. left), 7 flushes with 5 min intervals (u. right), 10 flushes with 10 min intervals (I. left), and 20 flushes with 3 min intervals (I. right). 

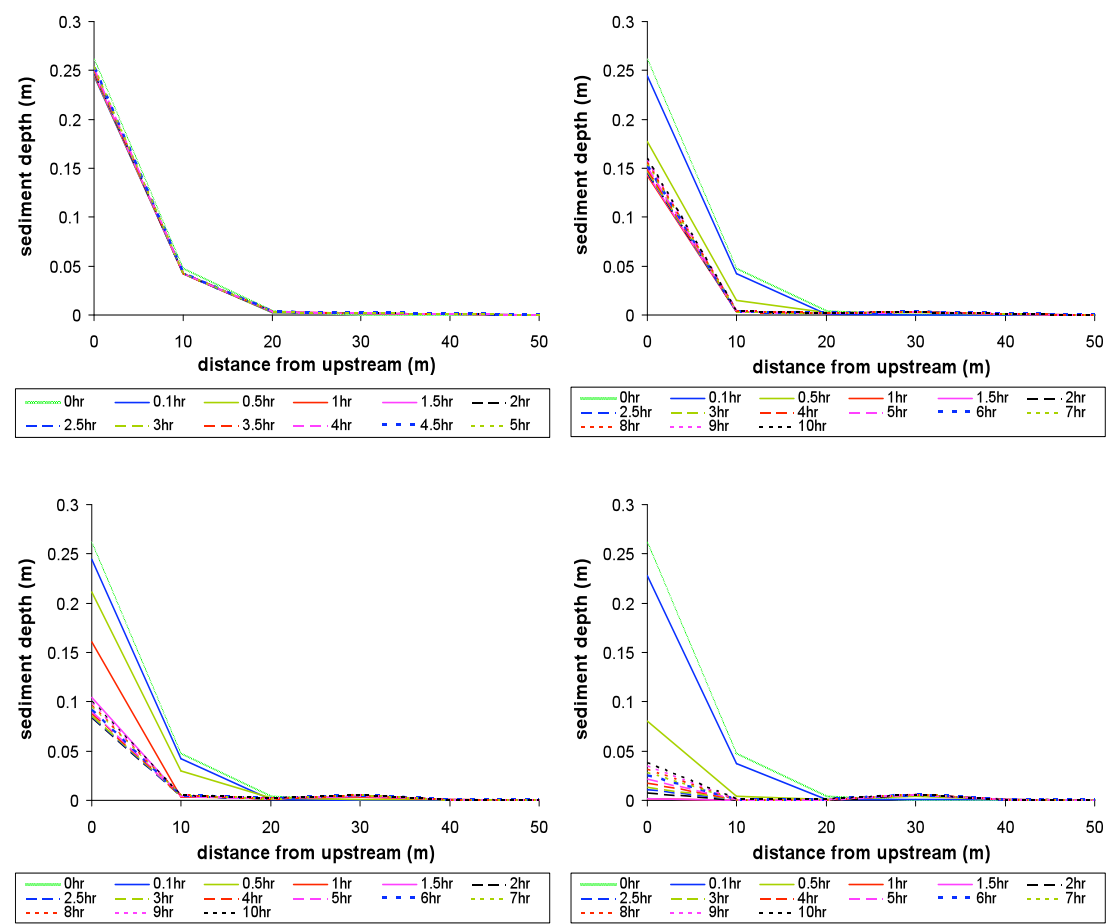

Figure 7.13 Sediment erosion in the conduit with slope $=0.002 \mathrm{~m} / \mathrm{m}$ and particle $d_{50}=0.9 \mathrm{~mm}$ due to the effect of flushes: 1 flush ( $\mathrm{u}$. left), 7 flushes with 5 min intervals (u. right), 10 flushes with 10 min intervals (I. left), and 20 flushes with 3 min intervals (l. right).

These figures show that the rate of sediment erosion depends mainly on the invert slope of the sewers and also on the median size of the drifting sediment $\left(d_{50}\right)$. It was noticed that the ability of flushing waves to entrain and transport sediment particle was in direct relation with the invert slope of the sewer pipes. In fact, the aggravated shear stresses due to the flushes seemed to be unable to overcome the influence of lack of enough slopes in flat pipes and could not act much on sediment removal. In pipes with higher slopes $(\geq 0.003 \mathrm{~m} / \mathrm{m})$ the effects of flushes were clearly noticed and sediments were transported in an appropriate rate. In fact, weak flushing effects occurred in the network with relatively low pipe slopes $(<0.002 \mathrm{~m} / \mathrm{m})$ and comparatively large sediment particles $\left(d_{50}>1 \mathrm{~mm}\right)$ - see Figure 7.12 - while strong erosion occurred in the case 
of higher slopes $(>0.002 \mathrm{~m} / \mathrm{m})$ and finer sediments $\left(\mathrm{d}_{50} \leq 0.9 \mathrm{~mm}\right)$ - see Figure 7.13

\subsubsection{Sediment Build-up in DWF Period in Network}
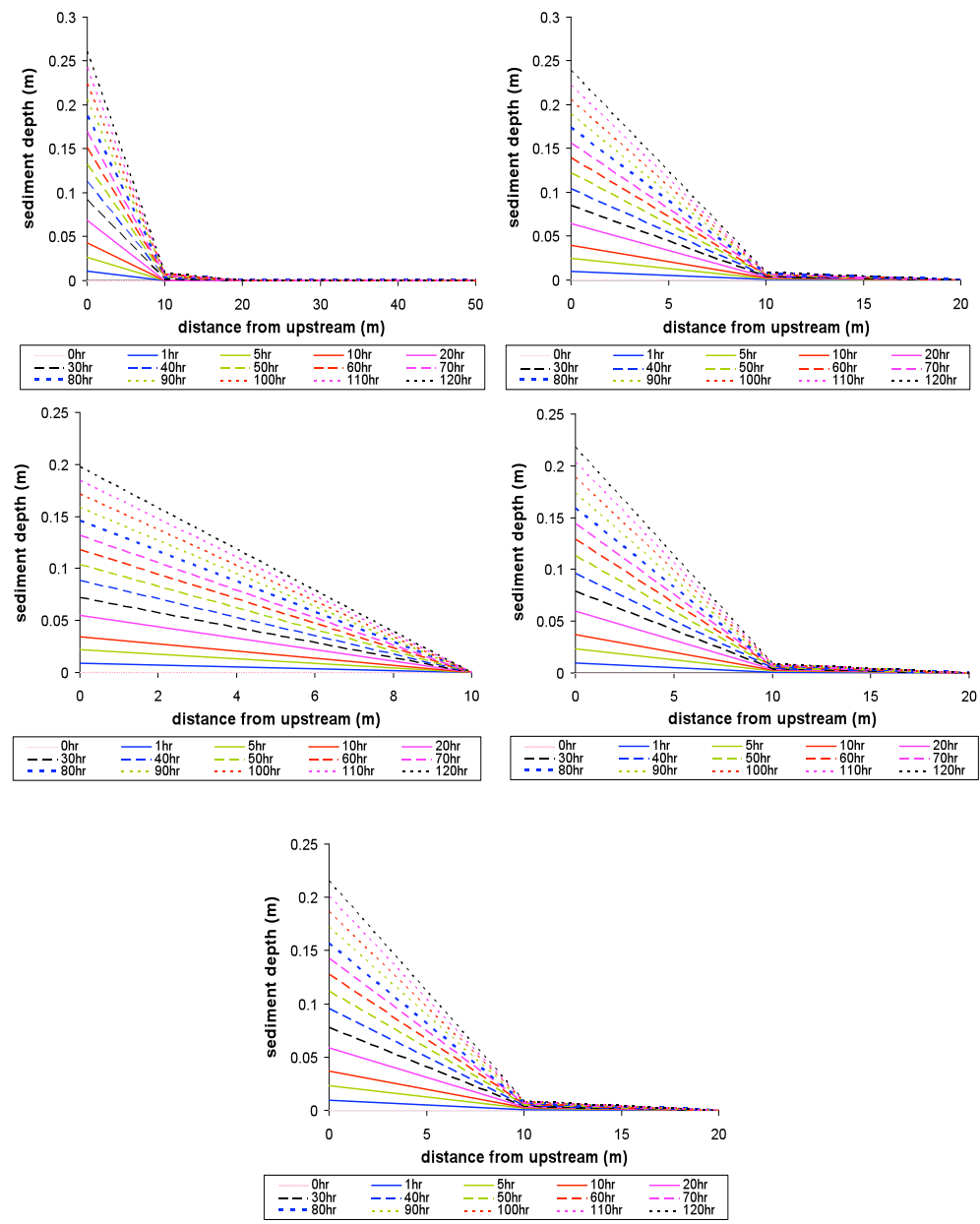

Figure 7.14 Sediment build-up in the sewer network with pipe slope = $0.002 \mathrm{~m} / \mathrm{m}$ and particles with $d_{50}=0.9 \mathrm{~mm}$ : $\mathrm{u}$. left, the main conduit (101-111-121-131-141-151); u. right, 201-211-111; c. left, 301-121; c. right, 401-411-131; and I. center, 501-511-141. 
The results for sediment build-up during DWF for the network model were also obtained and they were compatible with the ones for the conduit model. Therefore, the model could generate the sediment build-up along sewers in the network model in an acceptable way. The results corresponding to one certain network configuration is presented in Figure 7.14 above.

\subsubsection{Sediment Erosion by means of Flushes in Network}

The same as the conduit model, flushing events were modeled for the network model and the results were compared. The results showed that the model could generate the sediment erosion along sewers by means of flushing events in the network model in an acceptable way. One situation is presented in Figure 7.15.
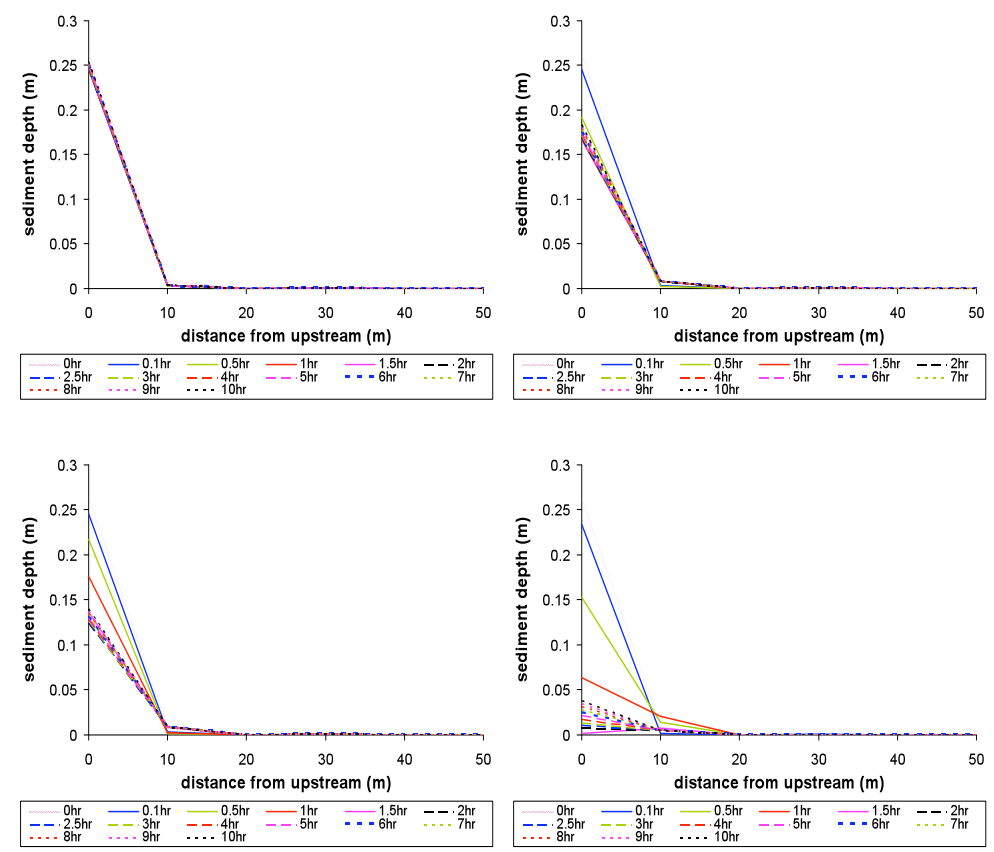

Figure 7.15 Sediment erosion in the main conduit (101-111-121-131141-151) due to the effect of flushes in the sewer network with pipe slope $=0.002 \mathrm{~m} / \mathrm{m}$ and particles with $d_{50}=0.9 \mathrm{~mm}: 1$ flush (u. left), 7 flushes with $5 \mathrm{~min}$ intervals (u. right), 10 flushes with $10 \mathrm{~min}$ intervals (I. left), and 20 flushes with 3 min intervals (I. right); see also Figure 7.7 above. 


\subsection{Conclusions}

It was discovered that modeling the DWF sediment build-up accurately was a preceding requirement in assessing the implementation of flushing tanks in sewer networks, because if the former part was not fulfilled properly, the latter one dealing with the erosion of the same settled particles cannot be accomplished in a reasonable way. In fact, sediment deposition modeling was a very sensitive task and required considered choice of the model parameters with physical basis. For instance, it was realized that the propensity for sediment deposition was different depending upon the location of a sewer in the network (i.e. the relative type of flow input) and the physical characteristics of the conduit especially its gradient.

Regarding the flushing tank implementations, various parameters such as network and sediment characteristics and flushing intervals were important in assessing whether the flushing tank was efficient in removing and transporting sediments in the considered sewer network. This study revealed that the type of sediment and main characteristics such as particle size and density, needed to be carefully considered in sediment transport modeling in order to obtain appropriate results.

In addition, frequent flushing had obvious effects on sediment erosion and transport in pipes; the higher the frequency of subsequent flushes, the less the chance for sediments to settle down in pipes. In fact, the subsequent flushes would intensify the hydraulic effects of the previous ones in removal and transport of the sediment through sewer pipes. Dettmar et al. (2002) mentioned that many small flow waves were able to move non-compact deposits and to work against new deposits, while big flow waves were able to loosen compact sediments. Moreover, the first flushes produce minor transport of deposited particles (but a more evident lowering) while for the successive flushes, the scoured section length increases more rapidly (Campisano et al., 2004).

By obtaining the simulation results and evaluating them, the compatibility of what was modeled with what would be expected was observed. The results showed that the model was moderately able to simulate the sedimentation of particles and their erosion by means of the flushes emitted from implemented flushing tanks. Also, the effect of various particle sizes and the pipe invert slopes on the processes of deposition and erosion has been modeled in a satisfactory way.

The effect of flush tank implementations on the modification of initial sediment beds and on sediment transport was noticeable. However, the effect of the flushing waves was restricted to a rather limited distance downstream of the 
flush tank due to effect of headlosses on the flow characteristics, that is, gradual reductions in carrying capacity of the flush wave. Nonetheless, in an overall perspective, the capability of such flushing tanks to produce effective forces for removal of the settled particles in sewer pipes is well accepted.

\section{Acknowledgments}

The authors express their gratitude to Keramo-Steinzeug to have given the opportunity to the Hydraulics Laboratory of the Katholieke Universiteit Leuven to accomplish the experiments on the flushing tank. We also are thankful to Wallingford Software for providing the essential software tool InfoWorks CS.

\section{References}

Ackers P. (1991). Sediment Aspects of Drainage and Outfall Design. In: Proceedings of the International Symposium on Environmental Hydraulics, ed. A.A. Balkema, Hong Kong. 16-18 December 1991.

American Society of Civil Engineers (ASCE) (1975). Sedimentation Engineering. Manuals and Reports on Engineering Practice, No. 54, ed. Vito A. Vanoni, New York, USA.

Ashley R.M. and Verbanck M. (1996). Mechanics of sewer sediment erosion and transport. Journal of Hydraulic Research, Vol. 34, No 6, pp. 753-769.

Ashley R., Bertrand-Krajewski J.-L. and Hvitved-Jacobsen T. (1998). Quo vadis sewer process modeling? In: Proceedings of the 4th International Conference on Developments in Urban Drainage Modeling (UDM'98), London, UK. 21-24 September 1998.

Ashley R.M., Bertrand-Krajewski J.-L., Hvitved-Jacobsen T. and Verbanck M. (2004). Solids in Sewers: Characteristics, Effects and Control of Sewer Solids and Associated Pollutants. Scientific and Technical Report No. 14. Joint Committee on Urban Drainage, Sewer Systems and Processes Working Group, IWA Publishing, London, United Kingdom. May 2004. ISBN: 1900222914.

Bertrand-Krajewski J.-L. (2002). Sewer Sediment Management: Some Historical Aspects of Egg-Shape Sewers and Flushing Tanks. In: Proceedings of the 3rd International Conference on Sewer Processes and Networks, Paris, France. 15-17 April 2002.

Bouteligier R., Vaes G. and Berlamont J. (2002). Transport Models for Combined Sewer Systems. Research project commissioned by Aquafin NV and Severn Trent Water Ltd., Hydraulics Laboratory, Katholieke Universiteit Leuven, Leuven, Belgium.

Bouteligier R., H.S.M. Shirazi R. and Berlamont J. (2006). Evaluation of the cleansing capacity of a flushing tank in (sanitary) sewer systems. In: Proceedings of the 7th International Conference on Urban Drainage Modeling and the 4th International Conference on Water Sensitive Urban Design, ed. A. Deletic and T. Fletcher, Melbourne, Australia. 2-7 April 2006. 
Campisano A. and Modica C. (2002). Flow velocities and shear stresses during flushing operations in sewer collectors. In: Proceedings of the 3rd International Conference on Sewer Processes and Networks, Paris, France. 15-17 April 2002.

Campisano A., Creaco E., Modica C. and Ragusa F. (2004). Laboratory Experiments on Bed Deposit Scouring during Flushing Operations. In: Proceedings of the 4th International Conference on Sewer Processes and Networks, Funchal, Madeira, Portugal. 22-24 November 2004.

Dettmar J., Rietsch B. and Lorenz U. (2002). Performance and Operation of Flushing Devices-Results of a Field and Laboratory Study. In: Proceedings of the 9th International Conference on Urban Drainage, ed. E.W. Strecker and W.C. Huber, Portland, Oregon, USA. 8-13 September 2002.

Dettmar J. and Staufer P. (2005). Behaviour of the Activated Storage-Volume of Flushing Waves on Cleaning Performance. In: Proceedings of the 10th International Conference on Urban Drainage, ed. Eriksson E., Genc-Fuhrman H., Vollertsen J., Ledin A., Hvitved-Jacobsen T. and Mikkelsen P.S., Copenhagen, Denmark. 21-26 August 2005.

Fraser A. and Ashley R. (1999). A Model for the Prediction and Control of Problematic Sediment Deposits. In: Proceedings of the 8th International Conference on Urban Storm Drainage, Sydney, Australia. 30 August-3 September 1999.

Fraser A., Schellart A., Ashley R. and Tait S. (2005). Prediction of sediment transport and filling rates of invert traps in combined sewers. In: Proceedings of the 10th International Conference on Urban Drainage (10ICUD), Copenhagen, Denmark. 21-26 August 2005.

Gerard C. and Chocat B. (1998). An Aid for the Diagnosis of Sewerage Networks: Analysis and Modeling of the Links between Networks' Physical Structure and the Risk of Sediment Build-up. In: Proceedings of the 4th International Conference on Developments in Urban Drainage Modeling, London, UK. 21-24 September 1998.

H.S.M. Shirazi R., Bouteligier R., Willems P. and Berlamont J. (2008). Preliminary Results of Investigating Proper Location of Flushing Tanks in Combined Sewer Networks for Optimum Effect. In: Proceedings of the 11th International Conference on Urban Drainage (11 ICUD), Edinburgh, Scotland, UK. 31st August-5th September 2008.

H.S.M. Shirazi R., Bouteligier R. and Berlamont J. (2008). Evaluation of Sediment Removal Efficiency of Flushing Devices Regarding Sewer System Characteristics. In: Proceedings of the International Conference on Hydro-science and Engineering, Nagoya, Japan. 8-12 September 2008.

May R.W.P. (2001). Minimum Self-cleansing Velocities for Inverted Sewer Siphons. In: Proceedings of the Urban Drainage Modeling (UDM) Symposium, part of the World Water Resources \& Environmental Resources Congress, ed. R.W. Brashear and C. Maksimovic, Orlando, Florida, USA. 20-24 May 2001.

Skipworth P.J., Tait S.J., Saul A.J. and Ashley R. (2001). Sewer flow quality modeling based on a novel deposit erosion model. In: Proceedings of the Urban Drainage Modeling (UDM) Symposium, part of the World Water Resources \& Environmental Resources Congress, Orlando, Florida, USA. 20-24 May 2001.

Stovin V.R., Schellart A.N.A., Tait S., Ashley R.M. and Burkhard R. (2005). Sewer invert trap design using laboratory and CFD models and continuous simulation. In: 
Proceedings of the 10th International Conference on Urban Drainage (10ICUD), Copenhagen, Denmark. 21-26 August 2005.

Wallingford Software (2008). InfoWorks CS Help, Wallingford Software Ltd., United Kingdom.

Zug M., Bellefleur D., Phan L. and Scrivener O. (1998). Sediment Transport Model in Sewer Networks - a New Utilisation of the Velikanov Model. Water Science and Technology, 37(1), pp 187-196. 